\title{
review
}

\section{Primary pulmonary choriocarcinoma}

\author{
Ziga Snoj, Igor Kocijancic, Erik Skof \\ 1 Institute of Radiology, University Medical Centre, Ljubljana, Slovenia \\ 2 Institute of Oncology, Ljubljana, Slovenia
}

Radiol Oncol 2017; 51(1): 1-7.

Received 18 March 2015

Accepted 20 May 2016

Correspondence to: Erik Škof, M.D., Ph.D., Institute of Oncology Ljubljana, Zaloška 2, SI-1000 Ljubljana, Slovenia. Phone: +386 5879 284; Fax: +386 5879 400; E-mail: eskof@onko-i.si

Disclosure: No potential conflicts of interest were disclosed.

Background. The aim of the study was to establish whether there are different clinical entities of primary pulmonary choriocarcinoma (PPC) that deserve different diagnostic approach and the most optimal treatment.

Patients and methods. A systematic review with PubMed search was conducted to identify studies that reported cases of PPC. The eligibility criteria were histological diagnosis of pulmonary choriocarcinoma and thorough examination of the reproductive organs to exclude potential primary choriocarcinoma in the gonads. Furthermore, to illustrate the review we additionally present a patient referred at our institution.

Results. 55 cases ( 17 men) were included in the review with a median age of 34 years. Women with the history of gestational event showed better survival outcome than women without the history of gestational event. Patients treated with combined modality treatment (surgery and chemotherapy) survived longer than the patients without combined modality treatment. Furthermore, multivariate analysis of prognostic factors showed that the combined modality treatment had independent prognostic significance. Size of the tumour showed significant prognostic influence in univariate and multivariate analysis.

Conclusions. PPC is an extreme rarity with variable clinical characteristics and outcome. It is important to capture and treat patients in the early stages of the disease. Women with the history of gestational event may show better survival, therefore genetic examination could help us to predict patient's prognosis. Surgery followed by adjuvant chemotherapy appears to represent the best treatment for PPC.

Key words: choriocarcinoma; pulmonary tumour; gestational event

\section{Introduction}

Choriocarcinoma is a germ cell tumour containing syncytiotrophoblastic cells and secreting human chorionic gonadotropin (hCG) hormone. Gestational choriocarcinoma originating in gonads frequently metastasizes to the lungs, but primary choriocarcinoma originating in the lung is a very rare entity. Primary extragenital choriocarcinoma most often arises in retroperitoneum, mediastinum and intracranially.

The mechanism of development of a primary pulmonary choriocarcinoma (PPC) is poorly understood. In the literature several theories have been postulated to explain the development of PPC: metastasis from primary gonadal choriocarcinoma that regressed spontaneously; origin from trophoblastic embolus related to gestational event after long period of latency; origin from retained primordial germ cells that migrate abnormally during embryogenesis; or a lung cancer that develops originally as non-trophoblastic neoplasm and later dedifferentiates. ${ }^{1-5}$

Lately a genetical examination helped to discriminate between gestational and nongestational origin of PPC. Maesta et al. proved with genetical examination that the PPC in both of their cases was of gestational origin. ${ }^{6}$ On the other hand, Vegh et al. excluded gestational origin with genetical examination, despite the patient had the history of gestational event. $^{7}$

PPC is a highly malignant intrapulmonary tumour with notoriously poor prognosis. Early diagnosis with optimal management is an impor- 
tant goal, since patients captured in early stages of the disease have higher survival rate. ${ }^{8}$ There is no standardized treatment for PPC. PPC grows rapidly and has high propensity to disseminate to other organs, such as bone, liver, brain, spleen and contralateral lung. ${ }^{4}$ Due to undifferentiated nature of malignancy, PPC has poor response to radiation treatment. ${ }^{9}$ The most appropriate regimen for chemotherapy seems to be BEP (bleomycin, methotrexate and cisplatin) or EMA-CO (etoposide, methotrexate, actinomycin D, cyclophospamide and vincristine). ${ }^{1,6,7,8,10}$ Despite the absence of randomized trials to prove its superiority, the combination of EMA-CO has become the preferred regimen for initial treatment of high-risk gestational trophoblastic disease in most countries. ${ }^{11}$

The aim of the article was to establish whether there are different clinical entities of PPC that deserved different diagnostic and therapeutic approach. Furthermore, to illustrate the review we additionally present a patient referred to our institution. In order to elucidate clinical characteristics and to determine optimal way of management of this rare neoplasm we analysed our patient together with other 54 reported cases.

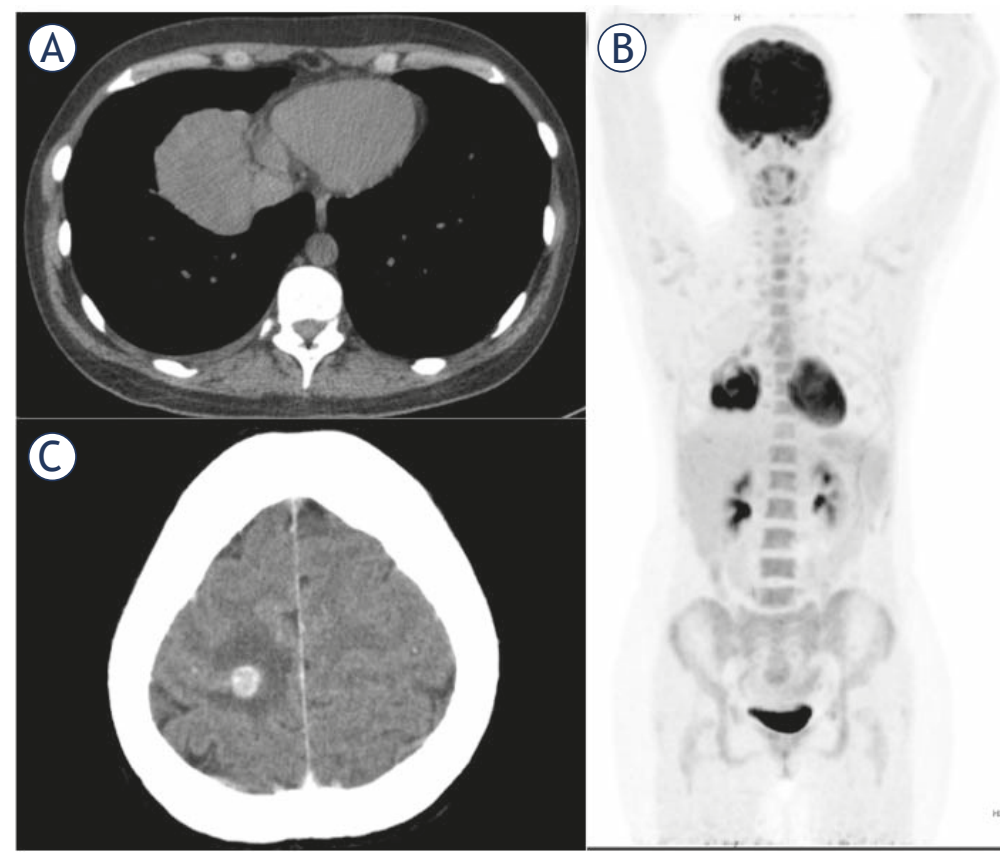

FIGURE 1. (A) A computed tomographic scan of the chest showing $6.4 \times 5.4 \times 5.9 \mathrm{~cm}$ pulmonary mass in right lower lobe. (B) FDG-PET study showing FDG accumulation in the pulmonary mass in the right lower lobe with no other abnormal accumulation found in whole body including pelvic cavity. (C) CT of the head showing $1 \mathrm{~cm}$ intracerebral mass with surrounding oedema.

\section{Patients and methods}

All published cases of PPC were collected with a PubMed search with the key word 'primary pulmonary choriocarcinoma' and the key word 'solitary pulmonary choriocarcinoma' that were published in English literature. The eligibility criteria were histological diagnosis of choriocarcinoma of the pulmonary tumour and thorough examination of reproductive organs to exclude potential primary choriocarcinoma in the gonads. Differences between patients groups according to gender were estimated using nonparametric Mann-Whitney test. Probabilities of survival were estimated using the Kaplan-Meier method and differences between patient groups were evaluated with the log-rank test. Prognostic factors were analysed using the Cox proportional hazard model. Reported values are twosided. Statistical significance was set at $\mathrm{p}<0.05$.

\section{The patient}

A 35 year old woman complaining of severe right sided chest pain was admitted to our hospital. The patient had three normal term deliveries in the past 15 years and three spontaneous abortions in the past year. The chest radiograph showed a round opacity in the right lungs. A computed tomographic scan (CT) of the chest revealed the presence of $6.4 \times 5.4 \times 5.9 \mathrm{~cm}$ pulmonary mass in the right lower lobe (Figure 1A). Transthoracic needle biopsy was performed and diagnosis of poorly differentiated giant cell carcinoma (GCC) was made. To exclude additional masses FDG-PET study was performed (Figure 1B). FDG accumulation in the pulmonary mass was low, maximum standardized uptake value (SUVmax) was 2.7, and only in the periphery of the mass. No other abnormal accumulation was detected in whole body including pelvic cavity. During hospitalization the patient's condition progresively worsened with depleting levels of hematocrit, hemoglobin and platelets. Urgent right sided bilobectomy with pericard excision was performed. Histopathologic workup of excised tumour showed poorly differentiated carcinoma with trophoblast differentiation, most consistent with choriocarcinoma. Excised nodes showed no tumour infiltration.

Four weeks after surgery the patient was admitted to our hospital to start chemotherapeutical treatment. In these four weeks the patient had two episodes of epileptical seizures. CT and MRI of the head showed $1 \mathrm{~cm}$ intracerebral metastasis with surrounding edema (Figure 1C). 
TABLE 1. Primary pulmonary choriocarcinoma: Summary of reported cases

\begin{tabular}{|c|c|}
\hline No of patients & 55 \\
\hline Gender, male/female & $17 / 38$ \\
\hline Median age all patients, years & 34 \\
\hline Median age female, years & 33 \\
\hline Median age male, years & 60 \\
\hline \multicolumn{2}{|l|}{ Initial symptom } \\
\hline Cough & 22 \\
\hline Dyspnea & 17 \\
\hline Hemoptysis & 14 \\
\hline Chest pain & 11 \\
\hline Asymptomatic & 8 \\
\hline \multicolumn{2}{|l|}{ Location } \\
\hline Right / Left lung & $29 / 18$ \\
\hline Right upper lobe & 11 \\
\hline Right middle lobe & 3 \\
\hline Right lower lobe & 15 \\
\hline Left upper lobe & 12 \\
\hline Left lower lobe & 4 \\
\hline Bilateral & 2 \\
\hline \multicolumn{2}{|l|}{ Tumor size, $\mathrm{cm}$} \\
\hline$\leq 5$ & 23 \\
\hline$>5, \leq 10$ & 13 \\
\hline$>10$ & 8 \\
\hline \multicolumn{2}{|l|}{ Treatment } \\
\hline s & 10 \\
\hline C & 8 \\
\hline RT & 3 \\
\hline$S+C$ & 24 \\
\hline$S+C+R T$ & 3 \\
\hline
\end{tabular}

$\mathrm{C}=$ chemotherapy; $\mathrm{RT}$ = radiotherapy; $\mathrm{S}=$ surgery

The patient began EMA-CO regimen chemotherapy with high dosage methotrexate. At the start of the chemotherapy plasma hCG levels were $169396 \mathrm{IU} / \mathrm{L}$, on eighth day fell to $20883 \mathrm{IU} / \mathrm{L}$ and after three months (4 cycles of chemotherapy) the plasma hCG levels fell within normal range. Patient underwent stereotactic radiotherapy of cerebral metastasis with dose 1 x 25 Gy after the fourth cycle and afterwards received two additional cycles of EMA-CO regimen with standard dose of metotrexate. To completely rule out the origin of the tumour in reproductive tract the vaginal total hysterectomy with bilateral salpingoectomy was performed after 6 cycles of chemotherapy and histopathological examination was negative.

According to FIGO clinical and prognostic staging patient had stage IV disease with high-risk score. ${ }^{12}$ Brain MRI was performed 7 months after stereotactic radiotherapy and showed $3 \mathrm{~mm}$ residual mass with no surrounding edema. Patient is on regular follow-up and is still on therapy with levetiracetam and dalteparin without evidence of relapse at 12 months following surgery.

The patient was treated according to the Helsinki Declaration. She gave a written informed consent before treatment to use her clinical data for research.

\section{Results}

\section{Patients}

We searched the literature with a PubMed search to establish characteristics of PPC using criteria described in Patients and methods. A review of the literature in English revealed 54 cases with previous report of primary choriocarcinoma originating in the lung. ${ }^{1-10,13-15,17-44}$ The patient described in the present paper was analysed with other 54 reported cases. The profiles of the patients are summarized in Table 1; 17 men and 38 women were included with a median age of 34 years (range 0.3 to 77 ). At the time of discovery 47 patients $(85 \%)$ produced symptoms, including persistent cough (40\%), dyspnea (31\%), hemoptysis (25\%) and chest pain (20\%). At presentation 8 tumours were asymptomatic. A few of the women have presented with hormonal problems such as amenorrhea or vaginal bleeding. In men, signs of feminisation such as gynecomastia have been observed but are uncommon.

\section{Correlation between gender and clinicopathological factors}

We analysed the relationship between gender and other clinicopathological features in patients with PPC (Table 2). Men were older than women ( $\mathrm{p}=$ $0.000)$. Men had the history of smoking more often than women $(p=0.000)$. No statistically significant difference between genders was observed for location, size, presence of metastases, history of haemoptysis or treatment.

\section{Survival}

Only 47 cases (16 men and 31 women) reported treatment outcome. The median survival time was 
(A)

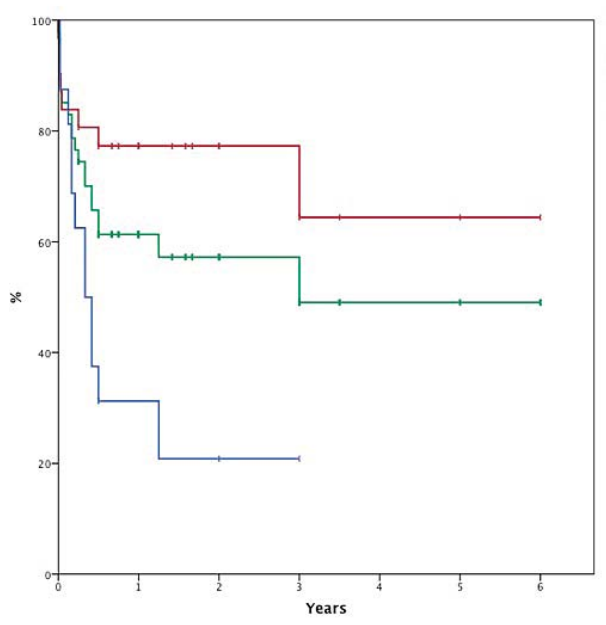

All patients, $n=47$

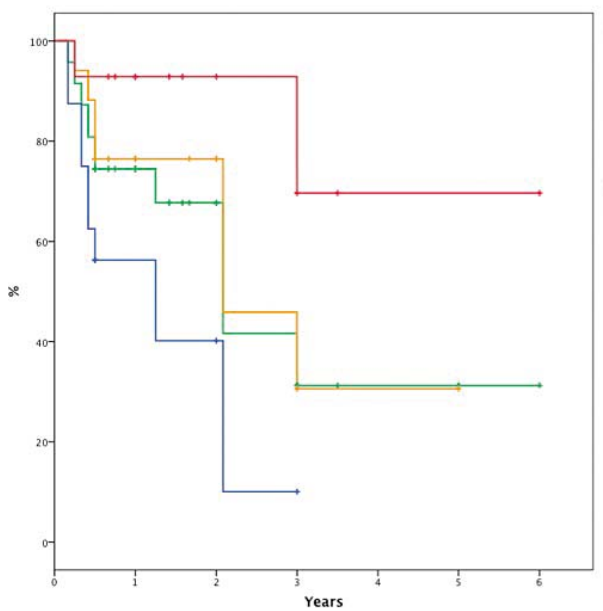

$\overline{\text { All patients, } n=47}$

(B)

Years
Women

with positive

gestational

history, $n=14$

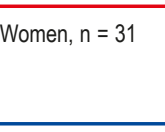

Men, $n=16$

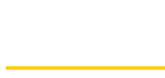

Women with

negative

gestational

history, $n=17$

Men, $n=16$

FIGURE 2. Kaplan-Meier survival curves. (A) Survival for all reported cases with curves showing survival for female patients was longer than for male patients ( $p$ $=0.004)$. (B) Survival of all reported cases with survival of men and curves showing survival of female patients with the history of gestational event was longer than for female patients without the history of gestational event ( $p=0.040$ ).

8 months. The review of these 47 cases showed 1-, $2-$, and 5- year survival rates of $61 \%, 57 \%$ and $49 \%$, respectively. Important difference $(p=0.004)$ in survival time between genders was observed with women showing 1-, 2-, and 5- year survival rates of $77 \%, 77 \%$ and $64 \%$ while men showed $1-, 2-$, and 5 - year survival rates of $31 \%, 21 \%$ and $21 \%$, respectively (Figure 2A).

In Table 3 univariate analysis is shown. Younger patients ( $<40$ years) survived longer than older patients ( $\geq 40$ years), $(p=0.009)$. Patients with smaller tumours $(<5 \mathrm{~cm})$ survived longer than patients with larger tumours $(\geq 5 \mathrm{~cm}),(p=0.000)$. Survival of patients without metastases at presentation was longer than for patients with metastases $(p=0.000)$. Patients without the history of smoking survived longer than patients with the history of smoking

TABLE 2. Differences between female and male patients primary pulmonary choriocarcinoma

\begin{tabular}{lllll}
\hline Characteristics & & Female & Male & p-value \\
\hline Age & $<40$ & 30 & 4 & \\
\multirow{2}{*}{ Size, cm } & $<40$ & 9 & 13 & 0.000 \\
& $<5$ & 17 & 7 & \\
Metastasis & Yes & 12 & 8 & 0.162 \\
\multirow{2}{*}{ Smoking } & No & 24 & 7 & 0.161 \\
\multirow{4}{*}{ Hemoptysis } & Yes & 2 & 9 & \\
& Yos & 13 & 5 & 0.000 \\
Treatment & No & 25 & 11 & 0.780 \\
S & Yes & 24 & 9 & \\
& No & 4 & 4 & 0.221 \\
C & Yes & 21 & 10 & \\
& No & 7 & 3 & 0.895 \\
S+C & Yes & 17 & 7 & \\
& No & 11 & 6 & 0.682 \\
\hline
\end{tabular}

$C=$ chemotherapy; $S=$ surgey

$(p=0.001)$. The women were further divided into two groups according to the history of gestational events (such as abortion, pregnancy or hydatiform mole) within the time period of less than 7 years prior the admission. Women with the history of gestational event $(n=14)$ had better survival outcome than women without the history of gestational event $(n=17)$, the difference was statistically significant $(p=0.040)$, (Figure $2 B)$. Patients treated with combination of surgery plus chemotherapy survived longer than those treated with optimal supportive care or either chemotherapy or surgery alone $(p=0.001)$. Patients treated with chemotherapy only survived less than the patients treated with surgery only or combination of chemotherapy and surgery $(p=0.016)$. Patients treated with combination of surgery and chemotherapy survived longer than patients without combination of surgery and chemotherapy $(p=0.010)$. Treatment with surgery demonstrated no significant prognostic influence.

As shown in Table 4, multivariate analysis of prognostic factors using the Cox proportional hazards model showed that the treatment combining surgery with chemotherapy had independent prognostic significance $(p=0.007)$. Furthermore, 
TABLE 3. Possible prognostic factors

\begin{tabular}{|c|c|c|c|c|c|c|}
\hline \multicolumn{2}{|c|}{ Characteristic } & \multirow{2}{*}{$\begin{array}{l}n \\
31\end{array}$} & \multirow{2}{*}{$\frac{\text { MST (months) }}{-}$} & \multirow{2}{*}{$\begin{array}{c}\begin{array}{c}1 \text {-year survival } \\
(\%)\end{array} \\
77.3\end{array}$} & \multirow{2}{*}{$\begin{array}{c}\begin{array}{c}\text { 2-year survival } \\
\text { (\%) }\end{array} \\
77.3\end{array}$} & \multirow[t]{2}{*}{ p-value } \\
\hline & Female & & & & & \\
\hline Gender & Male & 16 & 4 & 31.3 & 20.8 & 0.004 \\
\hline \multirow{2}{*}{ Age } & $<40$ & 29 & - & 75.9 & 58.4 & \\
\hline & $\geq 40$ & 18 & 4 & 33.3 & 33.3 & 0.009 \\
\hline \multirow{2}{*}{ Metastasis } & Yes & 21 & 4 & 42.9 & 0.95 & \\
\hline & No & 26 & - & 84.6 & 84.6 & 0.000 \\
\hline \multirow{2}{*}{ Smoking } & Yes & 11 & 4 & 0.0 & 0.0 & \\
\hline & No & 36 & - & 69.4 & 69.4 & 0.001 \\
\hline \multirow[t]{2}{*}{$S$} & Yes & 9 & - & 55.6 & 55.6 & \\
\hline & No & 32 & - & 71.0 & 64.5 & 0.458 \\
\hline \multirow[t]{2}{*}{ C } & Yes & 7 & 3 & 28.6 & 28.6 & \\
\hline & No & 34 & - & 75.8 & 69.9 & 0.016 \\
\hline \multirow[t]{2}{*}{$S+C$} & Yes & 24 & - & 83.3 & 56.3 & \\
\hline & No & 17 & 4 & 41.2 & 41.2 & 0.010 \\
\hline
\end{tabular}

$\mathrm{C}=$ chemotherapy; $\mathrm{MST}=$ median survival time; $\mathrm{S}=$ surgery

the size of the lesion showed an independent prognostic significance $(\mathrm{p}=0.008)$.

\section{Discussion}

In the present work we made a systematic review of the relevant literature. We found out that there are different clinical entities of PPC based on gender and reproductive history that show different survival. Furthermore, we showed it is important to capture and treat patients in the early stages of the disease. In addition we demonstrated that surgical treatment combined with chemotherapy is the best treatment regarding survival.

\section{Gender difference}

PPC occurs in women in younger ages than in men (33 vs. 60 median age), an observation already described by Umemori et al. ${ }^{8}$ Therefore, it can be derived that PPC in women is more likely to occur in the reproductive period. Furthermore, there are more reported cases with women than men.
Statistically significant difference in survival time between genders was observed with women showing better outcome. We further divided women in two groups due to the history of the gestational event within the time period of less than 7 years prior the admission. We chose the cut off of 7 years conservatively on the basis of three published cases with genetical examination. ${ }^{6,7}$ In the paper by Maesta et al. they present two patients with gestational event within 4 years prior to PPC diagnosis and in both cases they proved it to be of gestational origin. ${ }^{6}$ In the paper by Vegh et al. the patient had the last gestational event 7 years prior to admission and with fluorescence in situ hybridization they excluded gestational origin, no paternal chromosome was found in tissue examinated. ${ }^{7}$ Based on this assumption we considered that women with the history of gestational event less than 7 years had better survival outcome than women without such history of gestational event.

Looking at aforementioned gender differencies, PPC seems to be of different etiology in men. Furthermore, we showed that men have a history of smoking more often than women. To support 
TABLE 4. Multivariate analysis of prognostic factors, Cox proportional hazards model

\begin{tabular}{cccc}
\hline S+C & HR & $95 \% \mathrm{Cl}$ & p-value \\
\hline & & & \\
Yes & 0.147 & $0.036-0.598$ & 0.007 \\
No & 1 & & \\
Smoking & & & 0.423 \\
Yes & 1.827 & $0.418-7.982$ & \\
No & 1 & & \\
Gender & & & 0.776 \\
Male & 1.266 & $0.248-6.466$ & \\
Female & 1 & & 0.008 \\
Tumour size, cm & & & \\
$\geq 5$ & 6.622 & $1.622-27.031$ & \\
$<5$ & 1 & & 0.880 \\
Age, years & & & \\
$\geq 40$ & 0.879 & $0.164-4.703$ & \\
$<40$ & 1 & & \\
\hline
\end{tabular}

$\mathrm{C}=$ chemotherapy; $\mathrm{HR}=$ hazard ratio; $\mathrm{S}=$ surgery

the theory of dedifferentiation four cases of PPC have been reported with co-existent pulmonary carcinoma. ${ }^{5,10,13,14}$ All were male patients, in three cases PPC was sinchronous and found at autopsy, in one case the PPC was metachronous arising 6 years after diagnosis of squamous carcinoma. Problematically primary pulmonary carcinomas can produce hCG. Ikura et al. reported more intense expression of hCG in PPC than in hCG producing GCC. ${ }^{14}$ Although this finding seemed to reflect the level of serum hCG the cut off point seemed to be ambigous ${ }^{15}$ Because of the rarity and clinicopathological similarity of PPC and hCG producing GCC the criteria for distinguishing them are unclear and the diagnosis is very difficult. ${ }^{14}$

\section{Survival}

The survival data should be handled cautiously because of the possibility that mostly patients with good survival were reported in the literature and the rest were neglected. Nevertheless PPC is notorious for having a poor prognosis, however, the present review shows 1-, 2-, and 5- year survival rates of $61 \%, 57 \%$ and $49 \%$, which is reasonably good. Furthermore, if only female patients are observed the survival rates are even higher. Patients having smaller size tumour and being without metastases at diagnosis have higher survival rate, thus early diagnosis with optimal management is important. The outcome is still worrying but in comparison with the review article from the year 2004 by Umemori et al. where they reported 1-, 2-, and 5year survival rates of $41 \%, 34 \%, 34 \%$ the outcome results are more promising. We noticed that the early reports of PPC had poorer outcome than the ones nowadays and that chemotherapeutical treatment was rarely used in the cases prior to year 1994 but if chemotherapy was used it was single modality therapy. The evolvement of chemotherapeutical treatment and better supportive therapy could influence the better outcomes seen in the present review, but we could not attribute the difference in survival rates to the specific factor due to the rarity and nonexistence of therapeutic guidelines.

\section{Treatment}

In order of finding out any relationship between treatment and survival the univariate and multivariate analysis of prognostic factors was carried out. Univariate analysis showed that treatment with chemotherapy only is not good choice of treatment however significant prognostic influence for combined treatment with surgery and chemotherapy was found. Furthermore, multivariate analysis of prognostic factors revealed that combined treatment with surgery and chemotherapy had independent prognostic significance. These findings are in concordance with already known facts that PPC is very aggressive disease, not just locally, but also by early spread to other organs. ${ }^{4}$ Therefore, combined modality treatment (surgery and chemotherapy) represents best possible way to improve survival. Of course patients have to be fit enough for such aggressive treatment. No reports of extended survival were found in patients who underwent complete resection without chemotherapy.

\section{Conclusions}

PPC is an extreme rarity with variable clinical characteristics and outcome. It is important to capture and treat patients in the early stages of the disease. Women with the history of gestational event may show better survival, therefore genetic examination could help us to predict patient's prognosis. Surgery followed by adjuvant chemotherapy appears to represent the best treatment for PPC. 


\section{Acknowledgement}

We would like to thank M. Števanec for helping us with statistical analysis and Professor M. Snoj, M.D., Ph.D. for guidance with statistical interpretation.

\section{References}

1. Serno J, Zeppernick F, Jäkel J, Schrading S, Maass N, Meinhold-Heerlein I, et al. Primary pulmonary choriocarcinoma: case report and review of the literature. Gynecol Obstet Invest 2012; 74: 171-6.

2. Maruoka Y, Abe K, Baba S, Isoda T, Matsuo Y, Kubo Y, et al. A case of pulmonary choriocarcinoma metastasis with unusual FDG-PET and CT findings: correlation with pathology. Ann Nucl Med 2012; 26: 835-9.

3. Toda S, Inoue $\mathrm{Y}$, Ishino T, Yonemitsu N, Terayama K, Miyabara S, et al. A rare case of primary pulmonary choriocarcinoma in a male: immunohistochemical detection for human chorionic gonadotropin, epidermal growth factor (EGF) and EGF-receptor. Endocr J 1995; 42: 655-9.

4. Kini U, Babu MK. Primary pulmonary choriocarcinoma: Is it still an enigma? Indian J Chest Dis Allied Sci 2007; 49: 119-226.

5. Adachi H, Aki T, Yoshida H, Yumoto T, Wakahara H. Combined choriocarcinoma and adenocarcinoma of the lung. Acta Pathol Jpn 1989; 39:147-52.

6. Maestá I, Leite FV, Michelin OC, Rogatto SR. Primary pulmonary choriocarcinoma after human chorionic gonadotropin normalization following hydatidiform mole: a report of two cases. J Reprod Med 2010; 55: 311-6.

7. Vegh GL, Szigetvári I, Soltesz I, Major K, Batorfi J, Dancso J, et al. Primary pulmonary choriocarcinoma: a case report. J Reprod Med 2008; 53: 369-72.

8. Umemori Y, Hiraki A, Aoe K, Murakami T, Maeda T, Matsuda E, et al. Primary choriocarcinoma of the lung. Anticancer Res 2004; 24: 1905-10.

9. Sridhar KS, Saldana MJ, Thurer RJ, Beattie EJ. Primary choriocarcinoma of the lung: report of a case treated with intensive multimodality therapy and review of the literature. J Surg Oncol 1989; 41: 93-7.

10. Chen F, Tatsumi A, Numoto S. Combined choriocarcinoma and adenocarcinoma of the lung occurring in a man: case report and review of the literature. Cancer 2001; 91: 123-9.

11. Lurain JR, Singh DK, Schink JC. Primary treatment of metastatic high-risk gestational trophoblastic neoplasia with EMA-CO chemotherapy. J Reprod Med 2006; 51: 767-72.

12. Goldstein DP, Zanten-Przybysz IV, Bernstein MR, Berkowitz RS. Revised FIGO staging system for gestational trophoblastic tumors. Recommendations regarding therapy. J Reprod Med 1998; 43: 37-43.

13. Hayakawa K, Takahashi M, Sasaki K, Kawaoi A, Okano T. Primary choriocarcinoma of the lung: case report of two male subjects. Acta Pathol Jpn 1977; 27: 123-35.

14. Yamamoto S, Tanaka H, Takeo H, Yasuda K, Mastukuma S. Primary pulmonary choriocarcinoma combined with adenocarcinoma. Pathol Int 2006; 56: 402-7.

15. Ikura $\mathrm{Y}$, Inoue $\mathrm{T}$, Tsukuda $\mathrm{H}$, Yamamoto $\mathrm{T}$, Ueda $\mathrm{M}$, Kobayashi $\mathrm{Y}$. Primary choriocarcinoma and human chorionic gonadotrophin-producing giant cell carcinoma of the lung: are they independent entities? Histopathology 2000; 36: 17-25.

16. Marchevsky AM. Lung tumors derived from ectopic tissues. Semin Diagn Pathol 1995; 12:172-84.

17. Kay S, Reed WG. Chorioepithelioma of the lung in a female infant seven months old. Am J Pathol 1953; 29: 555-67.

18. Gerin-Lajoie L. A case of chorionepithelioma of the lung. Am J Obstet Gynecol 1954; 68: 391-401.

19. Acosta-Sison H. Can primary pulmonary chorionepithelioma develop after a term pregnancy? Case report. Am J Obstet Gynecol 1958; 76: 894-6.

20. Chan DP, Pang LS. Late solitary pulmonary chorionepithelioma following hydatiform mole. A report of three cases. J Obstet Gynaecol Br Commonw 1964; 71: 192-7.
21. Cacciamani J. Case of choriocarcinoma of the lung. Clin Notes Respir Dis 1971; 10: 10-1.

22. Bannayan GA, Woodruff JD, Shelley WM. Latent ectopic pulmonary choriocarcinoma associated with renal cell carcinoma. Am J Obstet Gynecol 1972; 114: 1009-11.

23. Kalla AH, Voss EC Jr, Reed RJ. Primary choriocarcinoma of the lung: (a case report). WV Med J 1980; 76: 261-3.

24. Zapatero J, Bellon J, Baamonde C, Aragoneses FG, Cubillo J, Orusco E, et al. Primary choriocarcinoma of the lung. Presentation of a case and review of the literature. Scand J Thorac Cardiovasc Surg 1982; 16: 279-81.

25. Patra SB, Giri DD, Patra BS. Giant choriocarcinoma of the lung. Indian J Chest Dis Allied Sci 1983; 25: 228-31.

26. Tanimura A, Natsuyama H, Kawano M, Tanimura Y, Tanaka T, Kitazono M. Primary choriocarcinoma of the lung. Hum Pathol 1985; 16: 1281-4.

27. Rhee YK, Kim JH, Kim WH, Ha CY, You KH, Jang DS. Primary choriocarcinoma of the lung. Korean J Intern Med 1987; 2: 269-72.

28. Pushchak MJ, Farhi DC. Primary choriocarcinoma of the lung. Arch Pathol Lab Med 1987; 111: 477-9.

29. Sullivan LG. Primary choriocarcinoma of the lung in a man. Arch Pathol Lab Med 1989; 113: 82-3.

30. Van Nostrand KM, Lucci JA, Liao SY, Di Saia PJ. Primary lung choriocarcinoma masquerading as a metastatic gestational neoplasm. Gynecol Oncol 1994; 53: 361-5.

31. Durieu I, Berger N, Loire R, Gamondes JP, Guillaud PH, Cordier JF. Contralateral haemorrhagic pulmonary metastases ("choriocarcinoma syndrome") after pneumonectomy for primary pulmonary choriocarcinoma. Thorax 1994; 49: 523-4.

32. Otsuka T, Ohshima Y, Sunaga Y, Nagashima K. Primary pulmonary choriocarcinoma in a four month old boy complicated with precocious puberty. Acta Paediatr Jpn 1994; 36: 404-7.

33. Canver CC, Voytovich MC. Resection of an unsuspected primary pulmonary choriocarcinoma. Ann Thorac Surg 1996; 61: 1249-51.

34. Aparicio J, Oltra A, Martínez-Moragón E, Llorca C, Gómez-Aldaraví L, Pastor M. Extragonadal nongestational choriocarcinoma involving the lung: a report of three cases. Respiration 1996; 63: 251-3.

35. Aras EL, López PG, Lago J, Muguruza I. Primary lung choriocarcinoma. Clin Transl Oncol 2001; 3: 107-9.

36. Arslanian A, Pischedda F, Filosso PL, Di Marzio P, Oliaro A, Fraire F, et al Primary choriocarcinoma of the lung. J Thorac Cardiovasc Surg 2003; 125: $193-6$.

37. Vaideeswar P, Mehta J, Deshpande J. Primary pulmonary choriocarcinoma-a series of 7 cases. Indian J Pathol Microbiol 2004; 47: 494-6.

38. Shintaku M, Hwang MH, Amitani R. Primary choriocarcinoma of the lung manifesting as diffuse alveolar hemorrhage. Arch Pathol Lab Med 2006; 130: 540-3.

39. Tajiri S, Ozawa H, Komatsu M, Hayama N, Kondo Y, Ito M, et al. A case of choriocarcinoma of suspected lung origin manifesting pulmonary embolism. Nihon Kokyuki Gakkai Zasshi 2008; 46:1029-33.

40. Corpa Rodríguez ME, Fernández Lahera J, Guadalajara Labajo $\mathrm{H}_{\text {, }}$ Vázquez Pelillo JC, Nistal Martín de Serrano M, García Sánchez-Giron J. Choriocarcinoma of the lung. Arch Bronconeumol 2009; 45: 153-5.

41. Seol HJ, Lee JH, Lee KY, Kim JH, Lee NW, Park HJ. Primary pulmonary choriocarcinoma presenting with a hemothorax. J Thorac Oncol 2009; 4: 653-5.

42. Hadgu A, Tindni A, Panda M. Primary pulmonary choriocarcinoma in a male. BMJ Case Rep 2010. doi: 10.1136/bcr.02.2010.2712.

43. Berthod G, Bouzourene H, Pachinger C, Peters S. Solitary choriocarcinoma in the lung. J Thorac Oncol 2010; 5: 574-5.

44. Ibi T, Hirai K, Bessho R, Kawamoto M, Koizumi K, Shimizu K. Choriocarcinoma of the lung: report of a case. Gen Thorac Cardiovasc Surg 2012; 60: 377-80.

45. Di Crescenzo V, Laperuta P, Napolitano F, Carlomagno C, Garzi A, Vitale M. An unusual case of primary choriocarcinoma of the lung. BMC Surg 2013; 13(Suppl 2): S33. 